\title{
Relationship between pressure pain threshold and coping strategies in patients with fibromyalgia
}

\author{
Ji-Young Song MD, Samuel Noh PhD, Manfred Harth MD FRCPC, Harold Merskey DM FRCPC FRCPsych
}

\author{
J-Y Song, S Noh, M Harth, H Merskey. \\ Relationship between pressure pain threshold and coping \\ strategies in patients with fibromyalgia. \\ Pain Res Manage 1998;3(1):23-32.
}

OBJECTIVE: To explore the hypothesis that the intensity of pain, pain thresholds and coping mechanisms differ between patients with fibromyalgia and those with rheumatoid arthritis (RA) in order to determine whether pain coping strategies contribute to the understanding of how patients adjust to fibromyalgia.

METHODS: Thirty-eight fibromyalgia patients were compared with 15 RA patients regarding severity of pain, pain history, pressure pain thresholds (measured with a pressure algometer) and pain coping strategies (measured with the Coping Strategies Questionnaire [CSQ]).

RESULTS: Fibromyalgia patients scored significantly higher than RA patients on severity of pain and had lower pain thresholds at three pairs of nontender sites than the RA group. Fibromyalgia patients were significantly different from RA patients with respect to catastrophizing and increasing behavioural activity, but this differentiation was not maintained with respect to the three main factors of the CSQ. Overall, both the fibromyalgia and RA groups resembled previous chronic pain populations. Depression and anxiety had strong negative correlations with the combined coping scores on the seven subscales $(\mathrm{P}<0.001)$.

CONCLUSIONS: Patients with fibromyalgia may use some distinctive coping strategies and tend to manage their pain in many of the same ways as other patients with chronic pain.

Key Words: Coping strategies, Fibromyalgia, Pain threshold, Rheumatoid arthritis, Trauma

\section{Rapport entre le seuil de la douleur à la pression et les stratégies d'adaptation à la douleur chez les patients atteints de fibromyalgie}

OBJECTIF : Explorer l'hypothèse selon laquelle l'intensité de la douleur, les seuils de la douleur et les mécanismes d'adaptation diffèrent entre les patients atteints de fibromyalgie et ceux atteints de polyarthrite rhumatoïde (PR) pour déterminer si les stratégies d'adaptation à la douleur peuvent nous aider à comprendre comment les patients s'adaptent à la fibromyalgie. MÉTHODE : Trente-huit patients fibromyalgiques ont été comparés à 15 patients atteints de PR relativement à la sévérité de la douleur, l'historique de la douleur, les seuils de la douleur à la pression (mesurés avec un algomètre à pression) et les stratégies d'adaptation à la douleur (mesurées avec le Coping Strategies Questionnaire [CSQ]).

RÉSULTATS : Les patients atteints de fibromyalgie ont obtenu des scores nettement plus élevés que les patients atteints de PR en ce qui concerne la sévérité de la douleur et présentaient, à trois points bilatéraux non douloureux, des seuils à la douleur moins élevés que le groupe atteint de $P R$. Les patients fibromyalgiques étaient très différents des patients atteints de PR en ce qui concerne l'inquiétude et la tendance à la rumination et l'augmentation de l'activité comportementale, mais cette différenciation disparaissait en ce qui concerne les trois principaux facteurs du CSQ. Globalement, le groupe de fibromyalgiques et celui atteint de PR ressemblaient aux autres populations atteintes de douleur chronique et étudiées précédemment. La dépression et l'anxiété présentaient des corrélations fortement négatives avec les scores d'adaptation combinés sur les sept sous-échellles $(\mathbf{P}<0,001)$.

CONCLUSION : Les patients atteints de fibromyalgie pourraient avoir recours à des stratégies d'adaptation spécifiques et ont tendance à gérer leur douleur la plupart du temps de la même manière que les autres patients atteints d'une douleur chronique.

Department of Psychiatry, Kyung Hee University, Seoul, Korea; Clarke Institute of Psychiatry, University of Toronto, Toronto, Ontario; Department of Psychiatry and Department of Medicine, Division of Rheumatology, University of Western Ontario, London, Ontario

Correspondence and reprints: Dr H Merskey, London Health Science Centre, University Campus, 339 Windermere Road, London, Ontario

N6A 5A5. Telephone 519-663-3515, fax 519-663-3935

Received for publication October 21, 1996. Accepted July 29, 1997 
$F^{i}$ bromyalgia is a common chronic pain syndrome characterized particularly by diffuse musculoskeletal pain in the presence of abnormal tenderness at predesignated sites, stiffness and fatigue (1-3). Despite extensive research efforts, no distinctive tissue pathology or psychopathology has been found $(4,5)$, and the nature of the diagnostically mandatory tender points remains elusive. Nevertheless, there is a relationship with sleep disturbances in some cases (6), and there are biochemical changes, particularly elevation of substance $\mathrm{P}$ in the cerebrospinal fluid $(7,8)$, and reductions in somatomedin C (9) and serum tryptophan (10).

The lack of a definite pathophysiology led several investigators to examine the role of psychological and psychiatric factors in the presentation of symptoms associated with fibromyalgia. However, the role of psychological factors in fibromyalgia has been controversial. Anecdotal reports have portrayed fibromyalgia patients as anxious, tense, demanding, perfectionistic, driven, and hypersensitive to internal and external stimuli, but the results of psychosomatic studies have been equivocal $(5)$. Several studies $(11,12)$ found a significantly higher occurrence of psychological distress in fibromyalgia patients than in rheumatoid arthritis (RA) patients. Kirmayer et al (13) and Ahles et al (14) found no significant differences in the occurrence of psychiatric disorders (especially depression) between fibromyalgia patients and RA patients. We have not found a study in which fibromyalgia patients score less on psychological tests than RA patients, but some clinical samples have shown that patients with fibromyalgia tend to have more psychiatric illness than control patients.

Recent studies have underscored the importance of coping strategies as a determinant of the psychological adjustment of patients with a chronic disease such as RA $(15,16)$. In general, coping may be defined as "efforts to manage events that are perceived as stressful" (17). Individuals without chronic pain use a variety of methods to manage pain and pain-related stressors $(15,16,18,19)$. Recent research indicates that pain coping efforts are linked to physical and psychological function $(20,21)$, and that patients with chronic pain develop a wide variety of cognitive and behavioural strategies to help them cope with their pain (20). As with other chronic diseases, the variety of coping strategies that patients adopt may be partially responsible for the range of psychological adjustment found in fibromyalgia patients. In clinical experience, some fibromyalgia patients cope well with pain, and manage to lead active and satisfying lives, while others cope poorly and lead very restricted lives. In chronic disorders, it is worthwhile to examine the patterns of coping that patients employ.

Previous studies have found that medical status variables such as severity of psychological disturbance and pain threshold are related to fibromyalgia pain $(12,22-24)$. However, the relation of pain coping strategies to pain level, and physical and psychological adjustment in fibromyalgia has not been systematically investigated. Systematic evaluation of pain coping strategies may enable identification of those individuals likely to develop pain-related behaviour problems. Early treatment of these individuals by using behavioural and psychological interventions may reduce suffering and help them maintain a functionally effective lifestyle (16). It follows that the analysis of pain coping strategies, the inter-relationship of coping skills and the physical state of patients with fibromyalgia are clinically important and require further exploration. Such explora- tion is best accompanied by measurement of the levels of anxiety and depression in the patient studied.

Pain coping strategies that are adopted and used over prolonged periods of time may significantly affect physical and psychological functioning. In some patients, maladaptive coping patterns may become entrenched, thus heightening the severity of pain and the impact of pain on behaviour. In other patients, there is a possibility that coping patterns are simply all that a patient has managed to achieve in the face of relatively severe pain, and disruption of family life and circumstances. This problem is enlightened somewhat by the finding of Atkinson et al (25) that patients with back injuries are twice as liable to be depressed after their injury as before. Similarly, in a very long term prospective study, Magni et al (26) demonstrated that after allowing for demographic and situational variables, patients with chronic pain (defined only as pain present in the joints on most days in one month during the past year) were 2.85 times more likely than the general population to have depression. Because a history of accidents in patients who develop fibromyalgia is quite common, there is a need to account for the influence of such accidents. Further, when the possibility of compensation exists, there is always discussion of the influence of motivation in relation to compensation on adaptive behaviour and coping patterns. This influence has been recognized since the origin of compensation systems and has generated a large body of literature (reviewed in 27,28).

In this study, we sought to determine how coping strategies are related to current pain and functioning. The main question is, "Do pain coping strategies contribute significantly to our understanding of how patients adjust to fibromyalgia?", that is, are pain coping strategies related to severity of pain, chronicity of the illness and psychological distress after adjusting for demographic status and medical variables?

To evaluate these questions, the following three hypotheses were tested.

1) There will be significant differences in the reported levels of the severity (intensity) of pain and pain threshold between fibromyalgia and RA patients.

2) There will be significant differences in the reported scores of coping strategies between fibromyalgia and RA patients.

3) Coping strategies and differential exposures to trauma explain the differences in pain intensity and pain threshold between fibromyalgia and RA patients.

\section{PATIENTS AND METHODS}

\section{Patients}

Patients with fibromyalgia or RA were recruited from two university-based facilities, a rheumatology clinic and a pain-consultation and treatment service. Patients with fibromyalgia were recruited at both sites, and patients with RA were recruited only from the rheumatology clinic. Eligible patients were identified through medical chart reviews and were contacted sequentially during regular clinic visits over a five-week period. Patients with organic brain syndrome, schizophrenia or severe depressive illness, major communicative disorder, inability to communicate effectively in English, age under 18 years or over 65 years, or RA patients in functional class IV by the Steinbrocker criteria (29) were excluded from the study. 
Functional class IV patients are largely or wholly incapacitated, or confined to a wheelchair or bedroom, and are able to undertake little or no self-care. Informed consent was obtained from all study participants.

The research protocol was approved on ethical grounds by the Review Board for Health Science Research on Human Subjects of the University of Western Ontario, London, Ontario. In the clinical interests of the patients, medication could not be withdrawn for the study.

Patients with RA, which is a systemic, autoimmune disease involving chronic inflammation of the joints, typically serve as a control group because chronic pain of variable intensity and duration is the most significant and troublesome symptom of RA (30). Similar degrees of disability occur with pain and affections of the musculoskeletal system (31). RA has a specific and known etiology and, like fibromyalgia, is most common in women. Fibromyalgia subjects were diagnosed according to the criteria of the American College of Rheumatology (ACR) (2) and the International Association for the Study of Pain (32), which require widespread pain in combination with tenderness at 11 or more of 18 specific tender point sites. Subjects with RA were also diagnosed by using criteria of the ACR (33). At least four of the following symptoms indicate a diagnosis of RA: morning stiffness in and around joints lasting at least $\mathbf{~} \mathrm{h}$ before maximal improvement; soft tissue swelling of three or more joint areas; swelling of the proximal interphalangeal, metacarpophalangeal or wrist joints; symmetrical swelling; rheumatoid nodules; RA factor positive; and radiographic erosion.

Patients with concomitant RA and fibromyalgia were excluded. All patients with fibromyalgia who were asked to participate in this study agreed to do so. With three exceptions, all eligible patients with RA also agreed to take part.

\section{Methods}

Eligible patients were approached during their visits to the clinics. All patients were diagnosed by either Manfred Harth or Harold Merskey. Eighteen patients with fibromyalgia were approached at each centre, and all 36 agreed to take part. Of 18 patients with RA approached by Manfred Harth, 15 agreed to participate. The clinical characteristics of the patients were recorded in detail, and all patients received a semistructured interview that focused on the duration of pain, medication, history of surgical operations, and previous injury or illness.

The following were recorded in a standardized manner during the clinic visit.

Visual Analogue Scale for pain intensity and Likert-type verbal scale of pain: Intensity of pain was measured to control for the pain level in evaluating the effects of coping on adjustment (16). Patients with fibromyalgia and RA marked the severity of their current pain on a $10 \mathrm{~cm}$ Visual Analogue Scale (VAS), which was anchored by the terms "no pain" at the left end and "worst possible pain imaginable" at the right end $(34,35)$.

Coping Strategies Questionnaire: The Coping Strategies Questionnaire (CSQ) was used to measure patients' use of pain coping strategies (18). The CSQ has eight subscales, each consisting of six items. The subscales assess six cognitive strategies (diverting attention, reinterpreting pain sensation, coping self-statements, ignoring pain sensations, praying or hoping, and catastrophizing) and two behavioural strategies (increasing activity level and increasing pain behaviour). Subjects rated each item by using a seven-point scale to indicate how often they used that strategy to cope with pain $(0=$ never, 3 = sometimes and $6=$ always). At the end of the questionnaire, subjects made two separate ratings of the overall effectiveness of coping strategies. Thus, by using a seven-point scale, subjects rated how much control they had over pain $(0=$ no control, $3=$ some control and $6=$ complete control) and how much they were able to decrease pain $(0=$ cannot decrease it at all, $3=$ can decrease it somewhat and $6=$ can decrease it completely). The reliability of the CSQ subscales has been supported by Rosenstiel and Keefe (18) and Gross (39). Patients' scores on the CSQ were also converted to factor scores by using the factors and factor loadings described by Rosenstiel and Keefe (18). The three CSQ factors examined in the present study were cognitive coping and suppression, helplessness, and diverting attention and praying. These CSQ factors are associated with pain behaviour, functional disability, emotional adjustment and pain ratings after controlling for duration, financial compensation status, previous surgery and somatization (18). Following the suggestion of Rosenstiel and Keefe (18), the three main CSQ factors and their scores were used in the analysis.

Pressure pain threshold: The pressure pain threshold was measured over specific areas by using a dolorimeter (Pain Diagnostics and Thermography Inc, New York) in the manner described by Fischer (37). Six sites of nontender points were studied by dolorimeter, and measurements were recorded in $\mathrm{kg} / \mathrm{cm}^{2}$. The six sites (three pairs) were the upper arm over the lateral surface of the deltoid muscle $2 \mathrm{~cm}$ below the acromion process, the forearm at its dorsal distal third (2) and the mid-tibia (34). These points were not spontaneously tender to mild pressure before testing began $(37,38)$. The sequence of the testing sites was randomized.

Hospital Anxiety and Depression Scale: The Hospital Anxiety and Depression scale (HADS) (40) was specifically designed for use with patients suffering from physical illness and is an improvement on other self-assessments because it avoids items such as insomnia and anorexia that are as likely to result from physical illness as from mood disorder. The HADS is now widely used in both clinical and research settings. The HADS is a short, self-rating scale comprising seven items relating to depression and seven relating to anxiety, with a range of scores from zero to 21 . Case definition by a score of eight or more on either the anxiety or depression subscales has produced optimal results for depressive and anxiety disorder, respectively $(40,41)$.

Present Pain Intensity Scale: The Present Pain Intensity Scale asked patients to indicate whether they had mild pain, discomforting pain, distressing pain, horrible pain or excruciating pain (36). This constitutes a six-point scale with scores ranging from zero to five. The area to be tested was lightly palpated to identify the nontender area. Then, the dolorimeter was held close to the vertical position. Pressure was increased slowly and steadily at a rate of about $1 \mathrm{~kg} / \mathrm{s}$. The subject was asked to say "yes" when pain began (the pain threshold). All dolorimeter measurements were done by one of the authors (J-YS), who had engaged in previous study in this field.

Experience of trauma: Personal experiences with traumatic injury or accident were assessed during the semistructured interviews. First, subjects were asked if they had ever had an accident or bodily injury before. In the case of a positive response, the patient was 
TABLE 1

Demographic characteristics of patients with fibromyalgia and rheumatoid arthritis

\begin{tabular}{|c|c|c|c|}
\hline & $\begin{array}{l}\text { Fibromyalgia } \\
(\mathbf{n}=\mathbf{3 8})\end{array}$ & $\begin{array}{c}\text { Rheumatoid } \\
\text { arthritis }(n=15)\end{array}$ & $\mathbf{P}$ \\
\hline Age (mean $\pm \mathrm{SD}$ ) & $44.4 \pm 8.9$ & $53.0 \pm 8.7$ & 0.004 \\
\hline Sex (\% female) & 84.2 & 60.0 & NS \\
\hline $\begin{array}{l}\text { Marital status } \\
\quad(\% \text { married })\end{array}$ & 66.7 & 80.0 & NS \\
\hline $\begin{array}{l}\text { Education } \\
\quad(\text { mean years } \pm S D)\end{array}$ & $12.4 \pm 2.9$ & $12.8 \pm 2.1$ & NS \\
\hline Employed (\%) & 57.8 & 53.3 & NS \\
\hline Medication use (\%) & 84.2 & 100 & NS \\
\hline $\begin{array}{l}\text { Years since diagnosed } \\
\quad(\text { mean } \pm S D)\end{array}$ & $2.4 \pm 2.1$ & $11.8 \pm 12$ & 0.01 \\
\hline
\end{tabular}

NS Nonsignificant

asked whether chronic pain had developed following the injury and, if so, how long it had lasted. Finally, the patients' status on disability payments was coded.

\section{STATISTICAL ANALYSIS}

Data were analyzed by using SPSS/PC+. For the three hypotheses, Student's $t$ tests and $\chi^{2}$ tests were performed to compare group means and proportions. Multiple regression procedures were used to assess the extent to which coping and traumatic experience account for the link between fibromyalgia and either pain intensity or pressure pain thresholds (see hypotheses). For each of the two pain intensity measures and three pressure pain threshold ratings, the ef- fect of fibromyalgia (presence of) was estimated first, controlling for the effects of demographic characteristics. Then, the effect size was estimated again - this time controlling not only for the effects of demographic variables but also for the intervening variables (coping and trauma). The observed changes in the effect of fibromyalgia across the two models denote the portion of the effect of fibromyalgia on the outcome measures that is determined by either coping or trauma experiences. Statistical significance was set at the $P<0.05$ unless otherwise specified. All tests were two-tailed.

\section{RESULTS}

\section{Descriptive results}

Mean age of the fibromyalgia patients was approximately 44 years, nearly nine years younger than RA patients, and a large majority were female (Table 1). The two groups of patients were similar in terms of education and employment. Fibromyalgia patients were more likely to be married than patients with RA, perhaps due to their younger age. All RA patients were on medication, compared with $84.2 \%$ of fibromyalgia patients. These differences were noticeable, but statistical tests were not significant, except those for age. Most fibromyalgia patients had been diagnosed recently. On average, it had been less than 2.5 years since their illness was diagnosed. The mean duration of the specific illness among RA patients was almost five times as great as that of the fibromyalgia patients.

Comparisons of pain, accidents, injuries and illness in the two groups are presented in Table 2 . One patient with fibromyalgia did not have continuous pain. The rest $(\mathbf{9 7 . 3 \%})$ complained of pain at the time of examination. The RA group had a longer duration of pain (13.2 \pm 11.8 years, $P=0.23)$ than the fibromyalgia group $(9.2 \pm 7.1$ years). Fibromyalgia patients had suffered from more chronic pain before their present illness. Severity of pain in the fibromyalgia group, measured by verbal scales and VAS were $3.7 \pm 1.0$ and

TABLE 2

Pain, illness and injury in fibromyalgia and rheumatoid arthritis patients

\begin{tabular}{|c|c|c|c|c|}
\hline & Fibromyalgia $(n=38)$ & Rheumatoid arthritis $(n=15)$ & Comparison & $\mathbf{P}$ \\
\hline Pain (\% yes) & 97.3 & 66.7 & $\chi^{2}=7.27$ & 0.007 \\
\hline Duration of pain (years) & $9.2 \pm 7.1$ & $13.2 \pm 11.8$ & $t=1.23$ & 0.23 \\
\hline \multicolumn{5}{|l|}{ Severity of pain (mean $\pm S D$ ) } \\
\hline Pain intensity scales & $3.7 \pm 1.0$ & $2.4 \pm 0.8$ & $t=4.9$ & 0.001 \\
\hline Visual Analogue Scale (mm) & $54.0 \pm 26.3$ & $24.6 \pm 21.6$ & $t=4.18$ & 0.001 \\
\hline Number of operations & $2.5 \pm 1.9$ & $1.9 \pm 1.0$ & $t=1.5$ & 0.14 \\
\hline Accident or illness history (\% yes) & 81.5 & 26.6 & $\chi^{2}=12.1$ & 0.001 \\
\hline \multicolumn{5}{|l|}{ Type of injury or other illness (number) } \\
\hline Vehicle accident & 17 & 1 & & \\
\hline Work injury & 4 & 1 & & \\
\hline Viral infection & 1 & 0 & & \\
\hline $\begin{array}{l}\text { Combination of more than one of } \\
\text { the above }\end{array}$ & 5 & 0 & & \\
\hline Others & 5 & 2 & & \\
\hline None & 6 & 11 & & \\
\hline $\begin{array}{l}\text { Chronic pain before fibromyalgia or } \\
\text { rheumatoid arthritis illness (\% yes) }\end{array}$ & 68.4 & 20.0 & $\chi^{2}=16.3$ & 0.001 \\
\hline
\end{tabular}


TABLE 3

Comparison of the pressure pain thresholds and the Hospital Anxiety and Depression Scale in fibromyalgia and rheumatoid arthritis patients

\begin{tabular}{|c|c|c|c|c|}
\hline & $\begin{array}{c}\text { Fibromyalgia } \\
\quad(\mathbf{n}=\mathbf{3 8})\end{array}$ & $\begin{array}{l}\text { Rheumatoid arthritis } \\
(n=15)\end{array}$ & Comparison & $\mathbf{P}$ \\
\hline \multicolumn{5}{|l|}{ Pressure pain thresholds (mean $\pm \mathrm{SD}$ ) } \\
\hline Arm & $1.4 \pm 1.1$ & $2.1 \pm 0.8$ & $t=-2.65$ & 0.012 \\
\hline Forearm & $1.9 \pm 1.4$ & $2.9 \pm 1.1$ & $t=-2.65$ & 0.012 \\
\hline Tibia & $1.8 \pm 1.3$ & $2.5 \pm 0.7$ & $t=-2.46$ & 0.018 \\
\hline \multicolumn{5}{|l|}{ Hospital Anxiety and Depression Scale } \\
\hline Depression (mean \pm SD) & $9.8 \pm 4.1$ & $7.1 \pm 3.8$ & $t=-2.27$ & 0.03 \\
\hline Depression score eight or above (\%) & 78.9 & 33.3 & $\chi^{2}=8.05$ & 0.004 \\
\hline Anxiety (mean \pm SD) & $11.5 \pm 4.7$ & $8.7 \pm 4.9$ & $t=1.86$ & 0.74 \\
\hline Anxiety score eight or above (\%) & 81.5 & 60.0 & $\chi^{2}=1.66$ & 0.196 \\
\hline
\end{tabular}

TABLE 4

Comparisons of the subscales of the Coping Strategies Questionnaire and effectiveness rating between the two groups

\begin{tabular}{lcccc}
\hline Subscales & $\begin{array}{c}\text { Fibromyalgia } \\
\text { (mean } \pm \text { SD, } \mathbf{n = 3 8})\end{array}$ & $\begin{array}{c}\text { Rheumatoid arthritis } \\
\text { (mean } \pm \text { SD, n=15) }\end{array}$ & Comparison & P \\
\hline Diverting attention & $18.0 \pm 8.0$ & $16.0 \pm 9.0$ & $t=0.75$ & 0.46 \\
Reinterpreting pain sensation & $12.3 \pm 10.0$ & $7.9 \pm 6.7$ & $t=1.84$ & 0.07 \\
Coping self-statement & $22.9 \pm 5.3$ & $23.9 \pm 5.2$ & $t=-0.61$ & 0.54 \\
Ignoring pain sensation & $16.7 \pm 7.6$ & $14.6 \pm 6.8$ & $t=0.96$ & 0.34 \\
Praying or hoping & $19.4 \pm 8.8$ & $17.6 \pm 8.9$ & $t=0.65$ & 0.51 \\
Catastrophizing & $15.2 \pm 7.3$ & $8.8 \pm 6.9$ & $t=2.9$ & 0.006 \\
Increasing activity level & $18.8 \pm 5.8$ & $17.5 \pm 7.5$ & $t=0.61$ & 0.54 \\
Increasing pain behaviour & $21.5 \pm 6.3$ & $15.8 \pm 6.5$ & $t=2.85$ & 0.009 \\
Control over pain & $2.8 \pm 1.2$ & $3.6 \pm 1.0$ & $t=-2.21$ & $t$ \\
Ability to decrease pain & $2.8 \pm 0.7$ & $3.4 \pm 0.9$ & $t=-2.1$ & 0.03 \\
\hline
\end{tabular}

$54.0 \pm 26.3 \mathrm{~mm}$ (mean $\pm \mathrm{SD}$ ), respectively, both significantly higher than in the RA group, in accordance with the first hypothesis.

Fibromyalgia patients had many more prior accidents, of which motor vehicle accidents were the most common. They had experienced more injury or physical illness than RA patients.

Table 3 shows significant differences, as expected, in pain thresholds at three pairs of nontender points (arm, forearm and tibia) and in the depression scores on the HADS between the two groups. Fibromyalgia patients had low pressure pain thresholds, relatively more evidence of depression and increased anxiety.

Table 4 presents means and standard deviations for each of the CSQ subscales. When fibromyalgia alone was considered, patients with fibromyalgia were most likely to report frequent use of coping self-statements, praying or hoping, and increasing pain behaviour on the CSQ, while they used reinterpreting, ignoring pain sensation and catastrophizing less than other coping strategies. When fibromyalgia subscale scores on the CSQ were compared with those of the RA group, the fibromyalgia group showed significantly higher scores only on catastrophizing and increasing pain behaviour (equivalent to $\mathrm{P}<0.01$ after a Bonferroni correction). The latter subscale has revealed poor internal consistency for CSQ and is not usually presented as a subscale (42). The fibromyalgia group also had poor control over pain and low ability to decrease pain. No significant differences in CSQ scores examined by the three main CSQ factors were found between the two groups (Table 5).

To compare fibromyalgia patients in the current study with other pain populations, CSQ subscale means and $95 \%$ confidence intervals from the present sample were compared with those from previously published studies of patients with low back pain (43) and chronic pain (44) (Table 6). Fibromyalgia patients in the current study reported almost the same use of coping strategies, measured by the CSQ, as those in the other groups. They frequently used coping self-statement, and praying or hoping. Only the use of reinterpreting sensations was significantly different, being higher in the fibromyalgia patients than in both other groups $(P<0.05)$. These findings should be interpreted with caution because it is not certain 
TABLE 5

Comparison of the three main factors of the Coping Strategies Questionnaire between patients with fibromyalgia and those with rheumatoid arthritis

\begin{tabular}{lcccc}
\hline Factors & $\begin{array}{c}\text { Fibromyalgia } \\
\text { (mean } \pm \mathbf{S D}, \mathbf{n = 3 8} \text { ) }\end{array}$ & $\begin{array}{c}\text { Rheumatoid arthritis } \\
\text { (mean } \pm \text { SD, } \mathbf{n = 1 5} \text { ) }\end{array}$ & Comparison & \multicolumn{1}{c}{ P } \\
\hline Cognitive coping and suppression & $52.0 \pm 20.0$ & $46.5 \pm 13.5$ & $t=1.15$ & 0.257 \\
Helplessness & $45.2 \pm 10.6$ & $51.6 \pm 11.8$ & $t=-1.82$ & 0.081 \\
Diversion & $37.5 \pm 14.2$ & $33.7 \pm 15.5$ & $t=8.2$ & 0.422 \\
\hline
\end{tabular}

\section{TABLE 6}

Coping Strategies Questionnaire subscales for patients with fibromyalgia, low back pain and chronic back pain

\begin{tabular}{|c|c|c|c|}
\hline Subscale & $\begin{array}{c}\text { Fibromyalgia } \\
(\text { mean } \pm S D, n=38)^{*}\end{array}$ & $\begin{array}{c}\text { Low back pain } \\
(\text { mean } \pm S D, n=62)^{\dagger}\end{array}$ & $\begin{array}{l}\text { Chronic back pain } \\
(\text { mean } \pm S D, n=62)^{\ddagger}\end{array}$ \\
\hline Diverting attention & $18.0 \pm 8.0$ & $16.1 \pm 8.5$ & $16.2 \pm 8.1$ \\
\hline Reinterpreting pain sensation & $12.3 \pm 10.0^{\S}$ & $5.40 \pm 6.8$ & $6.3 \pm 6.9$ \\
\hline Coping self-statement & $22.9 \pm 5.3$ & $19.4 \pm 6.5$ & $19.3 \pm 7.5$ \\
\hline Ignoring pain sensation & $16.7 \pm 7.6$ & $11.2 \pm 7.9$ & $12.6 \pm 8.3$ \\
\hline Praying or hoping & $19.4 \pm 8.8$ & $20.20 \pm 9.9$ & $20.1 \pm 8.3$ \\
\hline Catastrophizing & $15.2 \pm 7.3$ & $14.2 \pm 9.0$ & $14.3 \pm 6.9$ \\
\hline Increasing activity level & $18.8 \pm 5.8$ & $15.7 \pm 6.0$ & $17.0 \pm 6.0$ \\
\hline Control over pain & $2.8 \pm 1.2$ & $2.82 \pm 1.1$ & $2.7 \pm 1.2$ \\
\hline Ability to decrease pain & $2.8 \pm 0.7$ & $2.52 \pm 1.1$ & $2.6 \pm 1.2$ \\
\hline
\end{tabular}

${ }^{*}$ Data from current study; ${ }^{\dagger}$ From Keefe and Williams (21); ${ }^{\ddagger}$ From Crisson and Keefe (44); ${ }^{s} P<0.05$, fibromyalgia versus low back pain

whether the selection features and other conditions in the comparison studies were uniform with those of the present study. This reservation also applies to the following paragraph.

Mean subscale scores from the CSQ in the RA group were compared with those of patients from another published report with the same illness who underwent knee replacement (45) (Table 7). There were no significant differences in the use of coping strategies except for praying and hoping $(\mathrm{P}<0.05)$, which was higher in the knee replacement group. The latter group had the opportunity to focus on a specific event. This finding suggests that, apart from the finding on reinterpreting pain sensations, the coping strategies of the fibromyalgia group in this study are mostly similar to those of RA patients as well as to those of other chronic pain patient populations. Thus, with only one exception, the coping scores in different groups did not support our second hypothesis.

The relationships among the HADS, intensity of pain, pain threshold and coping scales scores were determined by using a correlation matrix for fibromyalgia and RA separately, and for the two groups combined. There were high negative correlations between the combined coping scores on the seven subscales, and either depression or anxiety $(r=-0.62$ for depression and $r=-0.61$ for anxiety, $\mathrm{P}<0.001$ ). The inverse correlations of depression and anxiety with the ability to decrease pain in the CSQ were also fairly strong $(r=-0.524, \mathrm{P}<001$ for depression; $\mathrm{r}=-0.48, \mathrm{P}<001$ for anxiety).

The three combined coping strategy variables had relationships of $r=-0.339$ with the VAS $(P<0.1)$ and $r=-0.408(P<0.01)$ with the verbal report of pain, while the ability to decrease pain had correlations of $r=-0.385(\mathrm{P}<0.01)$ with the VAS and $\mathrm{r}=-0.48(\mathrm{P}<001)$ with the verbal report of pain. Other results in this matrix (eg, pain threshold) tended to follow corresponding patterns of correlation with coping scores, and with anxiety and depression, but these correlations were weaker. The ability to control pain also correlated negatively with depression and anxiety $(\mathrm{P}<0.01$ to $\mathrm{P}<0.001)$. The results demonstrate inverse relationships between psychological symptom scores, and both coping abilities and pain intensity.

\section{Fibromyalgia, coping and trauma}

Patients with fibromyalgia were about three times more likely to have experienced traumatic accidents or injuries in the past than patients with RA (Table 2). Over $81 \%$ of fibromyalgia patients had experienced accidents or injuries, or another illness, compared with less than $27 \%$ of the RA patients. Moreover, over $68 \%$ of fibromyalgia patients said they had chronic pain caused by accidents or injuries, while only $20 \%$ of the RA patients confirmed the onset of chronic pain following an accident $(\mathrm{P}<0.001)$. In the present study, 


\section{TABLE 7}

Coping Strategies Questionnaire subscales for patients with rheumatoid arthritis (RA) and patients with $R A$ and knee replacement

\begin{tabular}{|c|c|c|}
\hline Subscale & $\begin{array}{c}\mathrm{RA} \\
(\text { mean } \pm \mathrm{SD}, \mathrm{n}=15)\end{array}$ & $\begin{array}{c}\text { RA with knee } \\
\text { replacement* } \\
\text { (mean } \pm S D, n=62)\end{array}$ \\
\hline Diverting attention & $16.0 \pm 9.0$ & $18.1 \pm 9.0$ \\
\hline $\begin{array}{l}\text { Reinterpreting pain } \\
\text { sensation }\end{array}$ & $7.9 \pm 6.7$ & $7.6 \pm 7.8$ \\
\hline $\begin{array}{l}\text { Coping } \\
\text { self-statement }\end{array}$ & $23.9 \pm 5.2$ & $25.1 \pm 9.3$ \\
\hline $\begin{array}{c}\text { Ignoring pain } \\
\text { sensation }\end{array}$ & $14.6 \pm 6.8$ & $15.4 \pm 8.7$ \\
\hline Praying or hoping $^{\dagger}$ & $17.6 \pm 8.9$ & $23.9 \pm 9.2$ \\
\hline Catastrophizing & $8.8 \pm 6.9$ & $7.1 \pm 6.7$ \\
\hline $\begin{array}{l}\text { Increased activity } \\
\text { level }\end{array}$ & $17.5 \pm 7.5$ & $18.6 \pm 7.7$ \\
\hline Control over pain & $3.6 \pm 1.0$ & $3.9 \pm 1.4$ \\
\hline $\begin{array}{l}\text { Ability to decrease } \\
\text { pain }\end{array}$ & $3.4 \pm 0.9$ & $3.3 \pm 1.3$ \\
\hline
\end{tabular}

${ }^{*}$ Results from Keefe et al (45); ${ }^{+} P<0.05$

the influence of accidents in relation to fibromyalgia is likely to be an artefact of the selection process, at least in part. Harold Merskey only contributed patients with fibromyalgia and none with RA, and he sees a selected sample of patients with the chronic effects of injury. The duration of postinjury pain was also considerably extended for the fibromyalgia group, but the extent was not sufficiently large to establish statistical significance.

To examine the correlation of coping strategies with trauma, regression analyses of the three main factors of the CSQ were determined for the fibromyalgia group. The demographic and diagnostic group variables explained between $4 \%$ and $12 \%$ of the variances in strategies of coping ( $\mathrm{P}<0.1$ ), except for the strategy of diverting, which was strongly linked to female sex $(\mathrm{P}<0.01)$. No other important relationship was found. Trauma variables were not related to any of the coping strategies. In this respect, the result should be interpreted with caution because the numbers in the sample may not have been sufficient to demonstrate a negative finding after accounting for other variables. The correlation matrix reported above did show modest correlations between pain and coping variables.

Intervening or mediating role of coping and traumatic events The third hypothesis focused on examination of the intervening or mediating role of coping and trauma variables in explaining the increased levels of pain intensity, and the lower pain threshold of fibromyalgia patients. To examine this, a series of analyses were conducted, including examination of the results reported in Tables 2,3 and 5 , and bivariate correlations of those variables with the outcome measures (ie, pain intensity and pain threshold). A series of regression analyses were also performed. No coping variables were associated with measures of pain intensity or pressure pain thresh-

\section{TABLE 8}

Regressions of pain intensity measured by the Visual Analogue Scale and verbal scales

\begin{tabular}{lcccc}
\hline & \multicolumn{2}{c}{ Visual Analogue Scale } & \multicolumn{2}{c}{ Verbal scale } \\
$\begin{array}{l}\text { Predictor } \\
\text { variables }\end{array}$ & Model I & Model II & Model I & Model II \\
\hline Fibromyalgia & $0.508^{* *}$ & $0.257^{*}$ & $0.517^{* *}$ & $0.358^{*}$ \\
Age & 0.227 & $0.363^{*}$ & 0.019 & 0.084 \\
Female & 0.221 & 0.173 & 0.087 & 0.042 \\
$\begin{array}{l}\text { Accident and/or } \\
\quad \text { injury }\end{array}$ & & 0.029 & & 0.164 \\
$\begin{array}{l}\text { Chronic pain due } \\
\text { to accident }\end{array}$ & & $0.419^{*}$ & & $0.401^{*}$ \\
$\begin{array}{l}\text { Duration of pain } \\
\text { Disability } \\
\text { payment }\end{array}$ & & -0.139 & & -0.026 \\
\begin{tabular}{l} 
Adjusted $R^{2}$ \\
\hline
\end{tabular} & 0.252 & 0.516 & 0.246 & 0.391 \\
\hline
\end{tabular}

Figures are standardized regression coefficients (Beta). These coefficients represent estimated partial correlations of each predictor with the dependent variable, controlling simultaneously for the effects of all other variables specified in the columns. ${ }^{*} P<0.05 ;{ }^{* *} P<0.01$

old. Hence, coping variables were not used in the final analyses (Tables 8, 9).

Table 8 presents the results of regression analyses of pain intensity. The left hand side of the table for the VAS indicates that after the effects of age and sex were controlled for, fibromyalgia patients had a substantially increased level of VAS scores compared with RA patients (Beta $0.508, \mathrm{P}<0.01$ ). This suggests that the size of elevation in VAS in the fibromyalgia group was equivalent to $50.8 \%$ of the standard deviation of the VAS. In model II, where the influences of trauma variables were also taken into account, the effects of fibromyalgia were reduced to a Beta of 0.257 . This change, a reduction of $49 \%$ of effect size, is due to the intervening influence of the four trauma variables, that is, $49 \%$ of the association between fibromyalgia and VAS was attributable to an indirect linkage with the trauma variable through their covariances. However, only two of the four intervening variables had significant roles $(\mathrm{P}<0.05)$. Previous exposure to an accident or injury did not explain the fibromyalgiapain association. The development of chronic pain after the accident or injury was crucial. The other significant mediating factor was receiving disability payments. Those who received disability payments described a higher pain intensity, and patients with fibromyalgia were more likely to be receiving such payments.

Similar patterns of results were found with the verbal scale of pain intensity, except that the mediating effects were somewhat reduced. The pain threshold levels were largely a function of the sex of the patients (Table 9); women tended to show substantially lower thresholds than men at all pressure points. When the effect of sex was controlled, there was little difference between fibromyalgia and RA patients, although this may be related to the small number of men involved. Likewise, trauma variables have little influence on the pain threshold scores. 


\section{TABLE 9 \\ Regressions of pressure pain thresholds}

\section{Pressure pain threshold}

\begin{tabular}{|c|c|c|c|c|c|c|}
\hline \multirow[b]{2}{*}{ Predictor variable } & \multicolumn{2}{|c|}{ Arm } & \multicolumn{2}{|c|}{ Forearm } & \multicolumn{2}{|c|}{ Tibia } \\
\hline & Model I & Model II & Model I & Model II & Model I & Model II \\
\hline Fibromyalgia & -0.202 & -0.139 & $-0.257^{*}$ & -0.099 & -0.179 & -0.063 \\
\hline Age & -0.140 & -0.203 & -0.196 & $-0.302^{*}$ & -0.161 & -0.254 \\
\hline Female & $-0.647^{* *}$ & $-0.623^{* *}$ & $-0.510^{* *}$ & $-0.498^{* *}$ & $-0.556^{* *}$ & $-0.535^{* *}$ \\
\hline Accident and/or injury & & -0.086 & & 0.085 & & -0.030 \\
\hline Chronic pain due to accident & & -0.100 & & -0.186 & & -0.157 \\
\hline Duration of pain & & 0.145 & & 0.147 & & 0.199 \\
\hline Disability payment & & $0.249^{*}$ & & 0.183 & & $0.259^{*}$ \\
\hline Adjusted $R^{2}$ & 0.438 & 0.459 & 0.252 & 0.321 & 0.304 & 0.339 \\
\hline
\end{tabular}

Figures are standardized regression coefficients (Beta). These coefficients represent estimated partial correlations of each predictor with the dependent variable, controlling simultaneously for the effects of all other variables specified in the columns. Model I is based on fibromyalgia, age and sex; Model II is based on all seven predictor variables. ${ }^{*} P<0.05 ;{ }^{*} P<0.01$

\section{DISCUSSION}

The purpose of the present study was to advance our understanding about patients with fibromyalgia. We hypothesized that patients with fibromyalgia would experience more intense pain and lower pressure pain thresholds than a RA control group. Furthermore, two constructs, coping and past traumatic experience, were hypothesized to explain an important portion of the elevated intensity of pain and lower pain thresholds among fibromyalgia patients.

The results of the study showed that fibromyalgia patients reported more severe pain, especially on the VAS, than RA patients. This was confirmed by multivariate analyses, but it is not a new finding. The more intense pain in fibromyalgia patients was independent of potential confounding factors, such as age and sex. We also found that previous accidents or injuries causing chronic pain, which were highly prevalent among fibromyalgia patients, explain an important portion of the increased pain intensity in these patients. Further, the two patient samples had similar coping strategies, and coping strategy did not correlate with pain intensity.

The high percentage of patients who had previous accidents in this study reflects the presence of patients who also had legal claims, past or pending. Status of compensation payments had some impact on the presentation and duration of chronic musculoskeletal pain complaints - that relationship being modulated by a variety of factors, including those involving motivation (28). However, there is no empirical support for the view that, as a group, chronic pain patients receiving compensation benefits or involved in litigation are less motivated than similar patients who do not receive financial benefits.

The phenomena of tenderness, worsening pain and hyperesthesia on clinical examination suggest that the pathogenesis of fibromyalgia may involve altered nociception. Reduced threshold and tolerance for pressure-induced pain at the standard tender points and at other 'control' points have been reported in patients with fibromyalgia $(46,47)$.

Our findings of pressure pain thresholds on the forearm and tibia
(1.9 \pm 1.4 and $1.8 \pm 1.3$, respectively) were close to those of Tunks et al (48) (2.06 \pm 0.64 and $1.80 \pm 0.76$, respectively). Our results for pain thresholds at nontender points were lower than those of Mikkelsson et al (49). The results from the latter study were 3.0 \pm 1.2 at the deltoid and 3.1 \pm 1.3 at the tibia. We confirmed findings of low pressure pain thresholds at nontender sites in patients with fibromyalgia. Also, fibromyalgia patients had significantly more severe pain than RA patients, which agrees with other studies $(39,50)$. This suggests that patients who have chronic fibromyalgia actually demonstrate a diffuse lowering of pain thresholds accompanied by a high intensity of pain as a primary problem. Nevertheless, being female was more strongly correlated with low pain thresholds than the diagnosis of fibromyalgia. With the influence of sex controlled, the impact of fibromyalgia on pain thresholds was minimal. There were no significant correlations between pressure pain thresholds and coping strategies.

It is thought that neurophysiological mechanisms contribute to the increased sensitivity and amplification of stimuli which, taken together with the amplified segmental reflexes, promote the syndrome of localized or generalized fibromyalgia (24). Scudds et al (38) suggested the generalized hypervigilance hypothesis that fibromyalgia patients are more aware of all perceptual experiences with an aversive tone, and pain just happens to be the primary one to which attention is directed. Hypervigilance reflects a perceptual style in which aversive events are amplified or in which the usual cognitive filtering mechanisms, which dampen the response to aversive events, are not fully engaged (51).

In a condition such as fibromyalgia, pain coping strategies may function as moderators of the adjustment to pain such that they may help patients tolerate and deal with their pain (52).

The CSQ assesses the use of cognitive coping and suppression, attention diversion and praying, and helpless mechanisms in pain management. Other research has found that coping strategies measured by the CSQ are predictive of pain, psychological function, activity level and physical impairment in chronic low back pain 
patients $(18,19)$. In our study, however, the three main factors of the CSQ did not correlate with the measures of pain or diagnosis.

Recently, Keefe et al (53) conducted a randomized, controlled study designed to determine whether a cognitive-behavioural intervention designed to improve pain coping skills could reduce pain, physical and psychological disability, and pain behaviour in osteoarthritic knee pain patients. They found that patients who received pain coping skills training had significantly lower levels of pain, and psychological and physical disability post-treatment than patients who received arthritis education. Evaluating pain coping skills in patients with fibromyalgia could give clues about how to reduce the level of pain and disability.

Compared with the RA group, the fibromyalgia group had higher scores on catastrophizing and increasing pain behaviour, and lower scores on control and decreasing pain by coping strategies. However, there was no significant difference between the two groups with respect to the three main factors of the CSQ. The fibromyalgia patient group used coping strategies similar to those of other chronic pain populations. The findings of the CSQ that patients with fibromyalgia tend to use pain coping strategies of coping self-statement, and praying or hoping, while having poor pain control and finding it difficult to decrease pain, may be characteristic of chronic pain and not specific to the fibromyalgia group.

The role of emotional factors in fibromyalgia is uncertain. Several investigators have shown that fibromyalgia patients report more psychological distress than RA patients or healthy controls $(12,14)$, but Clark et al (54) found no difference between fibromyalgia syndrome patients and a RA group. Our fibromyalgia sample had more depression but no more anxiety than the RA group. In both groups, depression and anxiety correlated negatively with coping skills and pain thresholds, but positively with intensity of pain.

Our study has several limitations that should be made explicit. Patients with RA were significantly older than patients with fibromyalgia; this is the general experience in our rheumatology clinic (personal communication). There was a larger percentage of men in the RA group than in the fibromyalgia group, reflecting the

\section{REFERENCES}

1. Yunus MB, Ahles TA, Aldag JC, Masi AT. Relationship of clinical features with psychological status in primary fibromyalgia. Arthritis Rheum 1991;34:15-21.

2. Wolfe F, Smythe HA, Yunus MB, et al. The American College of Rheumatology 1990 Criteria for the Classification of Fibromyalgia. Report of the Multicenter Criteria Committee. Arthritis Rheum 1990;33:160-72.

3. Mufson $M$, Regestein $Q R$. The spectrum of fibromyalgia disorders. Arthritis Rheum 1993;36:647-50.

4. Bennett RM. Confounding features of the fibromyalgia syndrome: A current perspective of differential diagnosis. J Rheumatol Suppl 1989;19:58-61.

5. Merskey $\mathbf{H}$. Physical and psychological consideration in the classification of fibromyalgia. J Rheumatol Suppl 1989;19:72-9.

6. Smythe HA, Moldofsky $H$. Two contributions to understanding of the "fibrositis" syndrome. Bull Rheum Dis 1977;28:928-31.

7. Vaeroy H, Helle R, Forre O, Kass E, Terenius L. Elevated CFS levels of substance $P$ and high instance of Raynaud phenomenon in patients with fibromyalgia: New features for diagnosis. Pain 1988;32:21-6.

8. Russell IJ. A metabolic basis for fibromyalgia syndrome. In: Vaeroy $\mathrm{H}$, Merskey H, eds. Progress in Fibromylagia and Myofascial Pain. Amsterdam: Elsevier Science, 1993:283-309.

9. Bennett RM, Clark SR, Campbell SM, Burckhardt CS. Low levels of somatomedin $\mathrm{C}$ in patients with the fibromyalgia syndrome: much larger prevalence of fibromyalgia than RA in women. The numbers in our groups may not have been sufficient to demonstrate certain true but small effects, such as influence of coping variables, especially in the regressions; however, the main purpose of the analysis was to determine the extent to which the link between diagnosis and pain was mediated by coping and other factors, and the evidence suggests that the influence of coping in that respect is not large.

Most patients with fibromyalgia were taking antidepressant, anxiolytic or antipsychotic medications, and nonsteroidal antiinflammatory medications. Disease modifying antirheumatic drugs and steroids were commonly used in the RA patients. These drugs may influence pain and the level of psychological distress. There is certainly overlap between the groups with respect to the drugs used, but we have not excluded some divergence. Narcotic use, other than combinations of acetaminophen and codeine, was rare. The latter combinations occurred in both groups, but exact figures were not collected. Fibromyalgia patients are likely to have used more analgesics, antidepressants and antipsychotics than RA patients. If anything, increased use of those drugs by the fibromyalgia group should have increased rather than reduced pressure pain thresholds (55). Selection factors were also prominent in the study. Subjects were recruited at a university-based rheumatology clinic and a psychiatric out-patient service, which anticipated a highly selected group of patients with fibromyalgia and RA. We assume that the sample is also biased towards those with more severe symptoms.

It is important that further research seek the best interventions that will enhance pain control and functional status in fibromyalgia patients who have persistent pain. Effective pain coping strategies could be useful in planning treatment interventions for patients likely to have persistent pain.

ACKNOWLEDGEMENTS: The authors acknowledge help and advice from Ms Mai Why, Dr GB Rollman, Ms C Hanas, Ms G Hudson and Ms J Duncan.

A possible link between sleep and muscle pain. Arthritis Rheum 1992;35:1113-6.

10. Yunus MB, Daily JW, Aldag DC, Masi AT, Jobe PC. Plasma tryptophan and other amino acids in primary fibromyalgia: A controlled study. J Rheumatol 1992;19:90-4.

11. Hudson JI, Pope HG Jr. Fibromyalgia and psychopathology: Is fibromyalgia a form of "affective spectrum disorder?". J Rheumatol Suppl 1989;19:15-22.

12. Payne TC, Leavitt F, Garron DC, et al. Fibrositis and psychologic disturbance. Arthritis Rheum 1982;25:213-7.

13. Kirmayer LJ, Robbins JM, Kapusta MA. Somatization and depression in fibromyalgia syndrome. Am J Psychiatry 1988;145:950-4.

14. Ahles TA, Khan SA, Yunus MB, Speigel DA, Masi AT. Psychiatric status of patients with fibromyalgia, patients with rheumatoid arthritis, and subjects without pain: A blind comparison of DSM-III diagnoses. Am J Psychiatry 1991;148:1721-6.

15. Brown GK, Nicassio PM, Wallston KA. Pain coping strategies and depression in rheumatoid arthritis. J Consult Clin Psychol 1989;57:652-7.

16. Keefe FJ, Caldwell DS, Queen KT, et al. Pain coping strategies in osteoarthritis patients. J Consult Clin Psychol 1987;55:208-12.

17. Lazarus RS, Folkman S. Stress, Appraisal, and Coping. New York: Springer, 1984.

18. Rosenstiel AK, Keefe FJ. The use of coping strategies in chronic low back pain patients: Relationship to patient characteristics and current adjustment. Pain 1983;17:33-44. 
19. Turner JA, Clancy S. Strategies for coping with chronic low back pain: relationship to pain and disability. Pain 1986;24:355-64.

20. Jensen MP, Turner JA, Romano JM. Self-efficacy and outcome expectancies: relationship to chronic pain coping strategies and adjustment. Pain 1991;44:263-9.

21. Keefe FJ, Williams DA. A comparison of coping strategies in chronic pain patients in different age groups. J Gerontol 1990;45:P161-5.

22. Uveges JM, Parker JC, Smarr KL, et al. Psychological symptoms in primary fibromyalgia syndrome: relationship to pain, life stress, and sleep disturbance. Arthritis Rheum 1990;33:1279-83.

23. Goldenberg DL. An overview of psychologic studies in fibromyalgia. J Rheumatol Suppl 1989;19:12-4.

24. Granges G, Littlejohn G. Pressure pain threshold in pain-free subjects, in patients with chronic regional pain syndromes, and in patients with fibromyalgia syndrome. Arthritis Rheum 1993;36:642-6.

25. Atkinson JH, Slater MA, Patterson TL, Grant I, Garfin R. Prevalence, onset, and risk of psychiatric disorders in men with chronic low back pain: a controlled study. Pain 1991;45:111-21.

26. Magni G, Moreschi C, Rigatti-Luchini S, Merskey H. Prospective study of the relationship between depressive symptoms and chronic musculoskeletal pain. Pain 1994;56:289-97.

27. Trimble MR. Post-traumatic Neurosis: From Railway Spine to Whiplash. New York: John Wiley \& Sons, 1981.

28. Mendelson G: Compensation and motivation in relation to musculoskeletal pain. In: Vaeroy H, Merskey H, eds. Progress in Fibromyalgia and Myofascial Pain. Amsterdam: Elsevier Science, 1993:101-12.

29. Steinbrocker $\mathrm{O}$, Trager $\mathrm{CH}$, Bateman $\mathrm{RC}$. Therapeutic criteria in rheumatoid arthritis. J Am Med Assoc 1949;140:659-62.

30. Skevington SM. Psychological aspects of pain in rheumatoid arthritis: A review. Soc Sci Med 1986;23:567-75.

31. Anderson KO, Bradley LA, Young LD, McDaniel LK, Wise CM. Rheumatoid arthritis: Review of psychological factors related to etiology, effects, and treatment. Psychol Bull 1985;98:358-87.

32. Merskey H, Bogduk N. Classification of Chronic Pain: Descriptions of Chronic Pain Syndromes and Definitions of Pain Terms. Seattle: International Association for the Study of Pain, 1994.

33. Amett FC, Edworthy SM, Bloch DA, et al. The American Rheumatism Association 1987 revised criteria for the classification of rheumatoid arthritis. Arthritis Rheum 1988;31:315-24.

34. Rollman GB. Measurement of pain in fibromyalgia in the clinic and laboratory. J Rheumatol Suppl 1989;19:113-9.

35. Harris G, Rollman GB. The validity of experimental pain measures. Pain 1983;17:369-76.

36. Melzack R. The McGill Pain Questionnaire: Major properties and scoring methods. Pain 1975;1:277-99.

37. Fischer AA. Pressure threshold meter: its use for qualification of tender spots. Arch Phys Med Rehabil 1986;67:836-8.

38. Scudds RA, Rollman GB, Harth M, McCain GA. Pain perception and personality measures as discriminators in the classification of fibrositis. J Rheumatol 1987;14:563-9.
39. Gross AR. The effect of coping strategies on the relief of pain following surgical intervention for lower back pain. Psychosom Med 1986;48:229-41.

40. Zigmond AS, Snaith RP. The hospital anxiety and depression scale. Acta Psychiatr Scand 1983;67:361-70.

41. Barczak P, Kane N, Andrews S, Cogdon AM, Clay JC, Betts T. Patterns of psychiatric morbidity in a Genito-urinary clinic: a validation of the Hospital Anxiety and Depression Scale (HAD). Br J Psychiatry 1988;157:860-4.

42. Swartzman LC, Gwadry FG, Shapiro AP, Teasell RW. The factor structure of the Coping Strategies Questionnaire. Pain 1994;57:311-6.

43. Keefe FJ, Crisson J, Urban BJ, Williams DA. Analyzing chronic low back pain: the relative contribution of pain coping strategies. Pain 1990;40:293-301.

44. Crisson JE, Keefe FJ. The relationship of locus of control to pain coping strategies and psychological distress in chronic pain patients. Pain 1988;35:147-54.

45. Keefe FJ, Caldwell DS, Martinez S, Nunley J, Beckham J, Williams DA. Analyzing pain in rheumatoid arthritis patients: pain coping strategies in patients who have had knee replacement surgery. Pain 1991;46:153-60.

46. Campbell SM, Clark S, Tindall EA, Forehand ME, Bennett RM. Clinical characteristics of fibrositis. I. A "blinded," controlled study of symptoms and tender points. Arthritis Rheum 1983;26:817-24

47. Simms RW, Goldenberg DL, Felson DT, Mason JH. Tenderness in 75 anatomic sites. Distinguishing fibromyalgia patients from controls. Arthritis Rheum 1988;31:182-7.

48. Tunks E, Crook J, Norman G, Kalaher S. Tender points in fibromyalgia. Pain 1988;34:11-9.

49. Mikkelsson $M$, Latikka $P$, Kautiainen $H$, Isomeri $R$, Isomaki $H$ Muscle and bone pressure pain threshold and pain tolerance in fibromyalgia patients and controls. Arch Phys Med Rehabil 1992;73:814-8.

50. Nolli M, Ghirelli L, Ferraccioli GF. Pain language in fibromyalgia, rheumatoid arthritis and osteoarthritis. Clin Exp Rheumatol 1988;6:27-33.

51. Rollman GB, Lautenbacher S. Hypervigilance effects in fibromyalgia: pain experience and pain perception. In: Vaeroy $\mathrm{H}$, Merskey $\mathrm{H}$, eds. Progress in Fibromyalgia and Myofascial Pain. Amsterdam: Elsevier Science, 1993:149-59.

52. Tan SY. Cognitive and cognitive-behavioral methods for pain control: a selective review. Pain 1982;12:201-28.

53. Keefe FJ, Caldwell DS, Williams DA, et al. Pain coping skills training in the management of osteoarthritic knee pain: a comparative study. Behav Ther 1990;21:49-62.

54. Clark S, Campbell SM, Forehand ME, Tindall EA, Bennett RM. Clinical characteristics of fibrositis. II. A "blinded," controlled study using standard psychological tests. Arthritis Rheum 1985;28:132-7.

55. Fishbain DA. Pain insensitivity in psychosis. Ann Emerg Med 1982;11:630-2. 


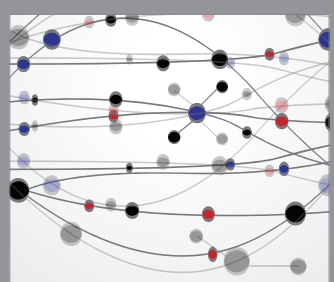

The Scientific World Journal
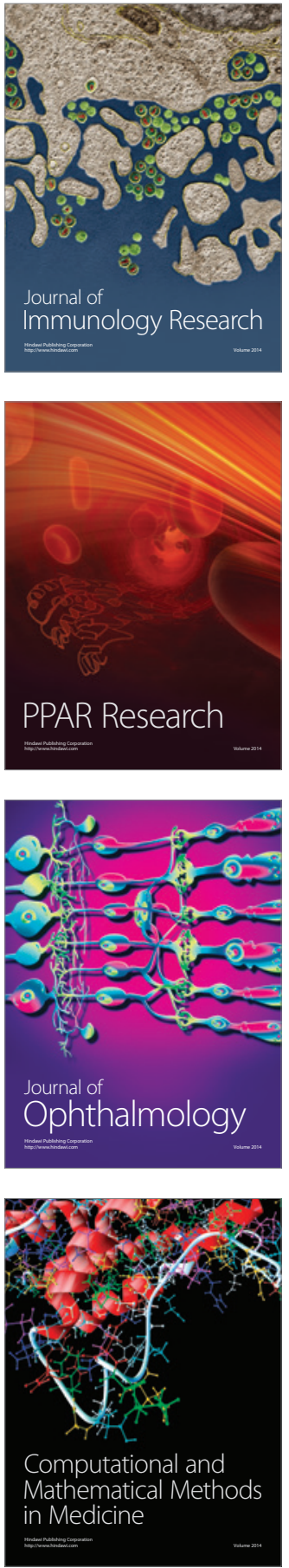

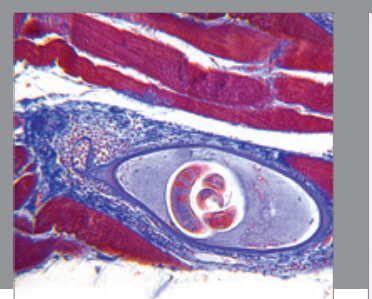

Gastroenterology Research and Practice

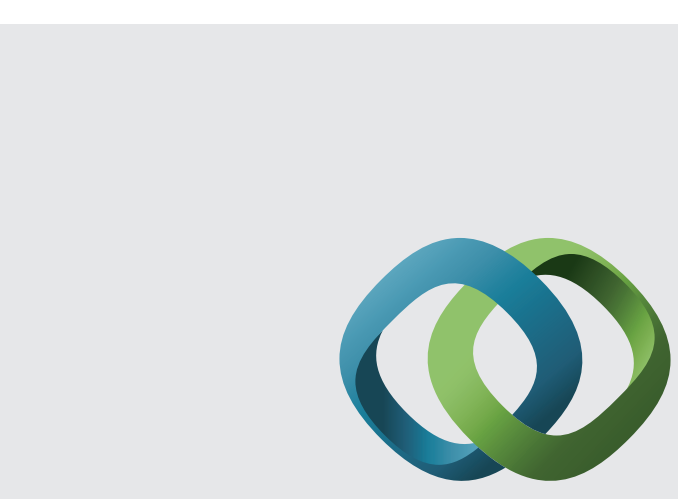

\section{Hindawi}

Submit your manuscripts at

http://www.hindawi.com
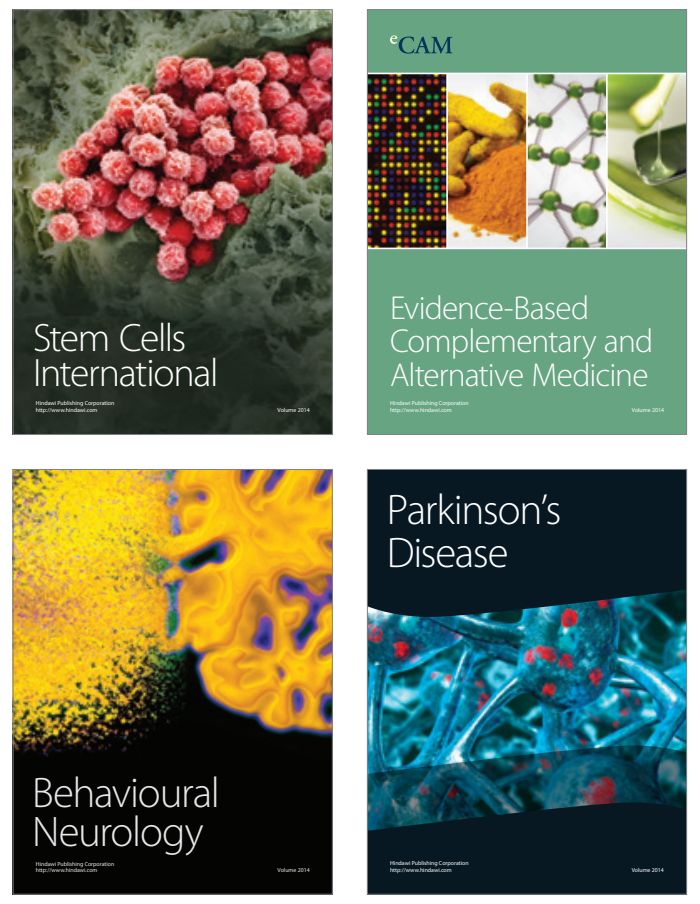
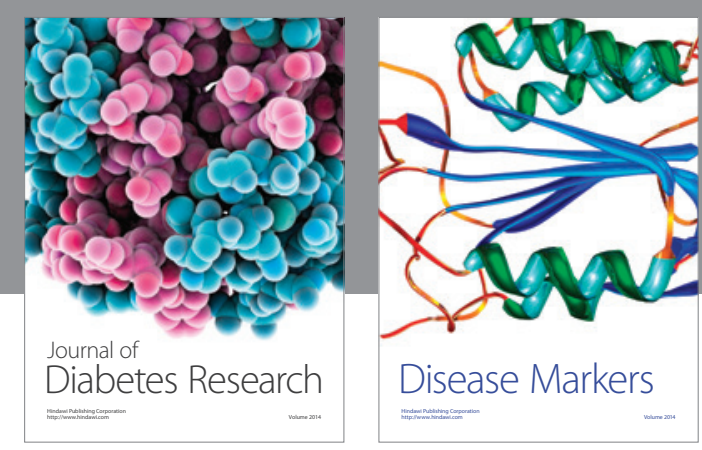

Disease Markers
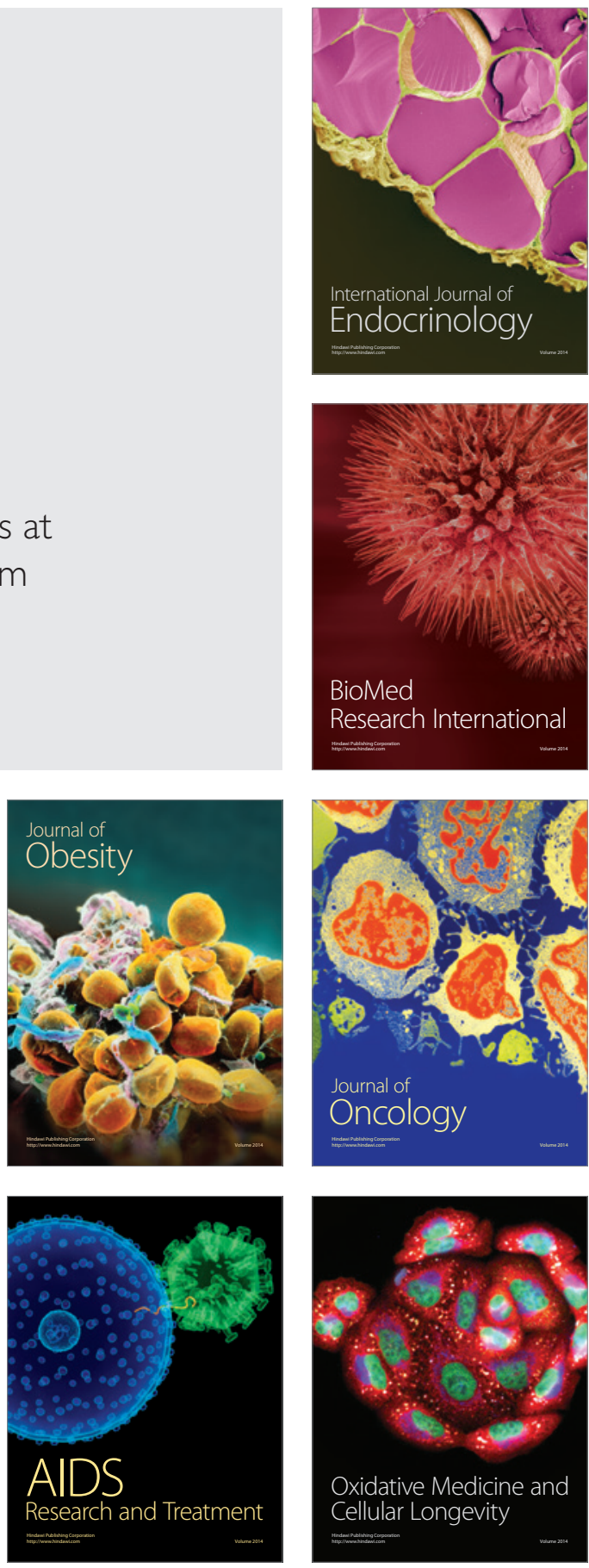